\title{
Oxidation of $\alpha$-Ketoaldehyde by Thiamine and Hydride Acceptor
}

\author{
A Chemical Model for a New Role of Thiamine \\ in the $\alpha$-Ketoaldehyde Metabolism ${ }^{1}$
}

\author{
Akira Takamizawa, Saichi Matsumoto \\ AND Itsuo MaKINo ${ }^{2}$ \\ Shionogi Research Laboratory, Shionogi and Co., Ltd., \\ Fukushima-ku, Osaka (Post No. 553)
}

(Received July 14, 1971)

\begin{abstract}
An adduct of phenylglyoxal with thiamine was readily converted to phenylglyoxylate and thiamine by the action of organic hydride acceptors such as 2,6dichlorophenol indophenol, trityl cation, 2-methyl-3-benzylidene-indolenium salt and $\mathrm{N}$-methylnicotinamide. Similar hydride transfer reaction was observed for the adduct of methylglyoxal with thiamine. Direct conversion of phenylglyoxal to phenylglyoxylate by 2,6-dichlorophenol indophenol was found to occur in the presence of TPP and base. The results indicate a new catalytic role for thiamine in the conversion of $\alpha$-ketoaldehyde to $\alpha$-ketoacid.
\end{abstract}

The two hitherto known pathways by which methylglyoxal can be metabolized to physiologically useful products are, firstly, conversion to D-lactate by the enzyme glyoxalase, requiring glutathione (GSH) as cofactor (1), and secondly direct oxidation to pyruvate by an enzyme named $\alpha$-ketoaldehyde dehydrogenase which requires pyridine nucleotide as cofactor, as recently proposed by Monder (2). There is, however, some evidence indicating that thiamine deficiency causes disorder of methylglyoxal metabolism in various species (3-5), though the role of thiamine in the metabolism of methylglyoxal has not been convincingly pointed out. In the course of studies on the nucleophilic reactivity of thiamine ylide, we have previously found (6, 7) that a number of $\alpha$-ketoaldehydes readily add to the thiazolium 2-position of thiamine to give 2-oxalylthiamine derivatives which are oxi- dized immediately upon contact with oxygen to yield thiamine thiazolone and the corresponding $\alpha$-ketoacids. From this observation we considered that thiamine must be capable of participating in the metabolic reactions of $\alpha$-ketoaldehyde, and we have undertaken the present investigation to examine a chemical model in which thiamine displays a catalytic role for the oxidation of $\alpha$-ketoaldehyde to $\alpha$-ketoacid. Although the $\alpha$-ketoaldehyde-thiamine adduct (I) can be readily oxidized to $\alpha$-ketoacid and thiamine thiazolone by the action of oxygen, this reaction cannot be regarded as a satisfactory model for the enzymatic reaction since the generation of thiamine thiazolone will stop the catalytic process. To find a better chemical model, therefore, we studied hydride transfer reactions of the adduct using some organic hydride acceptors including biologically related

\footnotetext{
1 This paper constitutes the part LXXVI of the series on Studies on Pyrimidine Derivatives and Related Compounds. Part LXXV was presented in Chem. Pharm. Bull., in press.

2 高見沢映, 松本佐市, 牧野逸男
} 


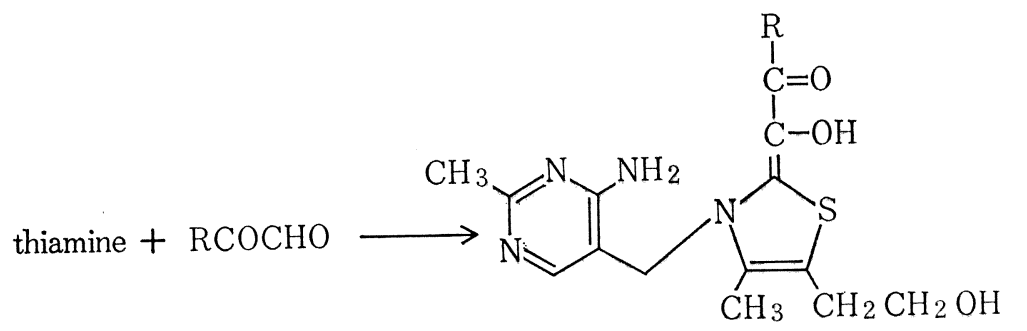

$\mathrm{Ia} ; \mathrm{R}=\mathrm{C}_{6} \mathrm{H}_{5}$

$\mathrm{Ib} ; \mathrm{R}=\mathrm{CH}_{3}$

FIG. 1.

compounds.

Oxidation of the adduct of phenylglyoxal with thiamine (Ia) $\left(\mathrm{R}=\mathrm{C}_{6} \mathrm{H}_{5}\right)$ by 2,6-dichlorophenol indophenol sodium salt (II) proceeded very rapidly at room temperature in ethanol under a nitrogen stream. The reaction was completed within one minute, and after acidification with diluted hydrochloric acid, $24 \%$ of phenylglyoxylic acid ethyl ester (IIIa) $(\mathrm{R}=$ $\left.\mathrm{C}_{6} \mathrm{H}_{5}\right), 27 \%$ of thiamine hydrochloride (IV) and $25 \%$ of 4,4'-dihydroxy-3,5-dichlorodiphenylamine (V) were isolated from the reaction mixture. By analogy with the biological process in which 2 -acetylthiamine or "active acetate" is involved as an intermediate in the oxidative decarboxylation of pyruvate (8), it seems likely that $\alpha$ ketoacylthiazolium complex (VI). is formed as intermediate in this oxidation reaction. 2-Acylthiazolium salts have been recognized as "high energy" compounds which are known to undergo

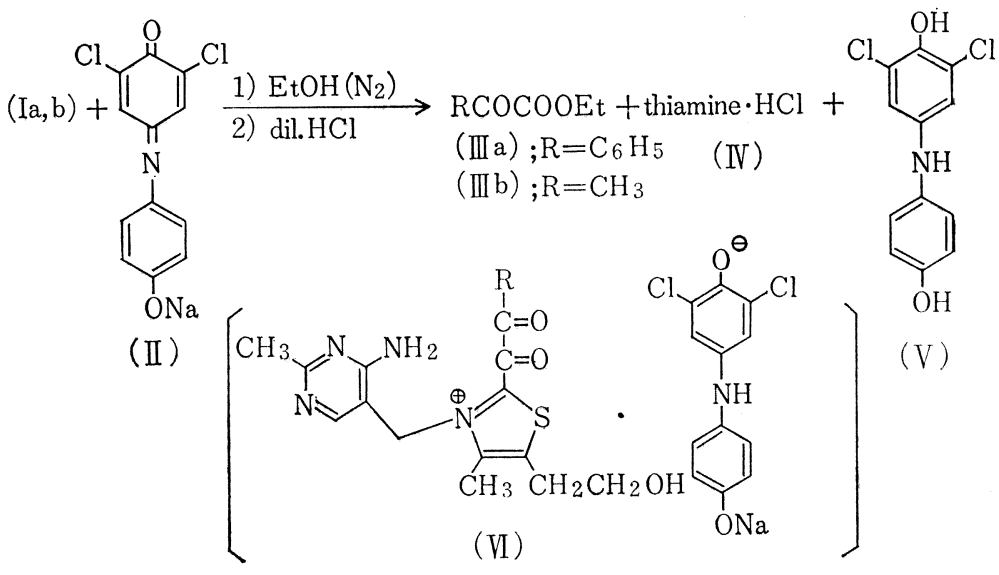

FIG. 2. facile solvolytic cleavage with liberation of a large amount of free energy $(9,10)$. Although $\alpha$-ketoacylthiazolium salts 'are thought to be even more unstable, and the intermediate (VI) could not be detected in the present reaction, the formation of the three products IIIa, IV and $\mathrm{V}$ is reasonably explainable by the alcoholysis of (VI). An analogous reaction with the formation of 2 acylthiazolium ion has been demonstrated in the oxidation of 2 - $\alpha$-hydroxyethyl-3,4-dimethylthiazolium salt (11).

The adduct of methylglyoxal with thiamine (Ib) $\left(\mathrm{R}=\mathrm{CH}_{3}\right)$, which was prepared according to the previously described method (7), also reacted with 2, 6-dichlorophenol indophenol (II) in ethanol to give thiamine $(35 \%)$ and the diphenylamine derivative (V) $(20 \%)$. In this case, however, the expected ethyl pyruvate (IIIb) $\left(\mathrm{R}=\mathrm{CH}_{3}\right)$ could not be detected in the reaction mixture, probably owing to a secondary reaction catalyzed by the regenerated thiamine.

Trityl cation was also found to be utilizable for the oxidation of $(\mathrm{Ia})$, although the reaction was less smooth than that of 2,6-dichlorophenol indophenol. Thus, stirring trityl chloride (VII) with Ia in ethanol for 20 hours at room temperature under a nitrogen stream gave thiamine monochloride (VIII) (24 $\%$ ), phenylglyoxylic acid ethyl ester (IIIa) $(20 \%)$ and a $1: 1$ mixture of triphenylmethane (IX) and triphenylmethyl ethyl ether (X) accompanied by a small amount of triphenylcarbinol (XI).

Next, we attempted the oxidation of Ia using biologically important hydride acceptors such as indolenium and nicotinamide salts, which are considered to be responsible for the mechanism of the action of various dehydrogenase enzymes (12-15). 


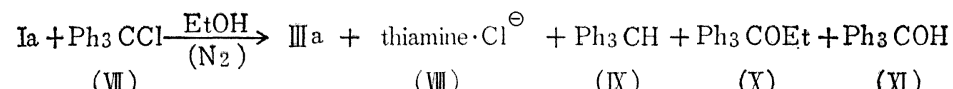

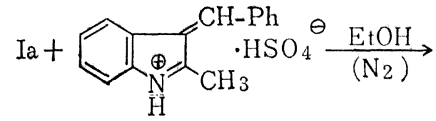

(XII)

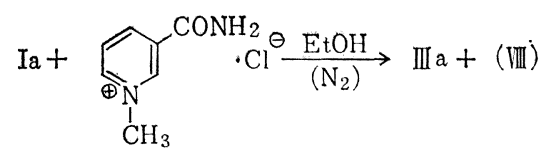

(XV)<smiles>Cc1[nH]c2ccccc2c1Cc1ccccc1</smiles>

(XII)

FIG. 3.

Reaction of 2-methyl-3-benzylideneindolenium hydrogen sulfate (XII) (16) with Ia in ethanol for 20 hours at room temperature under a nitrogen stream afforded $15 \%$ of phenylglyoxylic acid ethyl ester (IIIa), $19 \%$ of thiamine hydrogen sulfate (XIII), which was confirmed by converting to hydrochloride, and a small amount of 2-methyl-3-benzylindole (XIV) accompanied by a complex mixture of unidentified materials. Similarly, the reaction of Ia with N-methylnicotinamide chloride (XV) in ethanol gave $15 \%$ of IIIa and $10 \%$ of thiamine monochloride (VIII). Although the formation of dihydropyridine deivative (XVI) could not be confirmed in this case, it is considered that a reaction involving hydride transfer takes place, because no reaction was observed in the absence of oxygen without such a hydride acceptor.

The fact that thiamine is regenerated in these oxidation reactions is quite important, because it suggests that thiamine is capable of

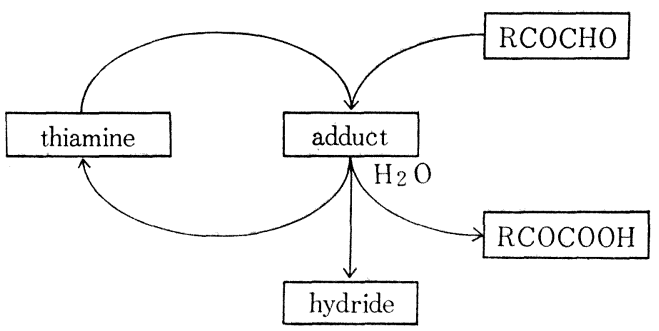

FIG. 4. catalyzing the oxidation of $\alpha$-ketoaldehyde to $\alpha$-ketoacid according to the cyclic process illustrated in the Fig. 4.

A model experiment using thiamine pyrophosphate (TPP) actually supported this suggestion. Although optimization of the reaction conditions was not attempted, the reaction of phenylglyoxal monohydrate (XVII) with 2, 6-dichlorophenol indophenol sodium salt (II) in the presence of 0.2 equivalents of TPP in ethanol containing triethylamine was found to give at least $25 \%$ yield of phenylglyoxylic acid ethyl ester (IIIa). In the absence of TPP, neither reduction of the hydride acceptor nor the formation of ester were observed.

$$
\underset{(\mathrm{XII})}{\mathrm{PhCOCHO} \cdot \mathrm{H}_{2} \mathrm{O}} \stackrel{\text { TPP-NEt } \left.3-\mathrm{EtOH}_{(\mathrm{N}}\right)}{\text { (II) }} \underset{\text { (IIIa) }}{\mathrm{PhCOCOOEt}}
$$

FIG. 5.

The results presented here lead us to conclude that the newly proposed pathway by which $\alpha$-ketoaldehyde is converted directly to $\alpha$ ketoacid is "chemically" possible. The previously reported observations (3-5) that thiamine deficiency is responsible for disorder of methylglyoxal metabolism encourages us to presume that a thiamine requiring enzyme system which catalyzes direct oxidation of methylglyoxal to pyruvate possibly exists in living tissues, although experimental verification remains to be given. If this is the case, the mode of enzyme action will be ascribed to model reactions described here.

\section{EXPERIMENTAL}

\section{Materials}

2,6-Dichlorophenol indophenol sodium salt, trityl chloride and $\mathrm{N}$-methylnicotinamide chloride were purchased from Tokyo Kasei Co. Ltd., and thiamine pyrophosphate (TPP) was purchased from Nakarai Chemicals, Ltd. Silica gel 
$\left(\mathrm{SiO}_{2}\right)$ used for column chromatography was grade 950 of Davision Chemical Co.. 2-Methyl3-benzylideneindolenium hydrogen sulfate was prepared according to a literature (16). Phenylglyoxal-thiamine adduct (Ia) was prepared by our previously reported method (7). Methylglyoxal-thiamine adduct (Ib) was also synthesized according to this method by reacting 42.5 $\mathrm{g}$ of thiamine sodium salt and $36 \mathrm{~g}$ of $40 \%$ aqueous $\mathrm{CH}_{3} \mathrm{COCHO}$ solution in $100 \mathrm{ml}$ of ethanol under a stream of dry $\mathrm{CO}_{2}$ gas with vigorous stirring for 3 hours at room temperature. On evaporating the reaction mixture under reduced pressure and washing the resulting mass adequately with water and then with ether, $11 \mathrm{~g}$ of $\mathrm{Ib}$ was obtained as a pale yellow solid melting at $124-128^{\circ}$ with decomposition. UV $\lambda \underset{\max }{\text { EtoH }}: 386 \mathrm{~m} \mu$. On acetylation with acetic anhydride in pyridine $\mathrm{Ib}$ gave a stable $\mathrm{O}, \mathrm{O}^{\prime}$ diacetate as colorless needles. mp. $181-182^{\circ}$. Anal. Calcd. for $\mathrm{C}_{19} \mathrm{H}_{24} \mathrm{~N}_{4} \mathrm{O}_{5} \mathrm{~S}: \mathrm{C}, 54.28 ; \mathrm{H}$. $5.75 ; \mathrm{N}, 13.33$; S, 7.61. Found: C, $54.01 ; \mathrm{H}$, $5.80 ; \mathrm{N}, 13.52 ; \mathrm{S}, 7.44$. UV $\lambda \underset{\max }{\mathrm{EtoH}}: 261 \mathrm{~m} \mu$. NMR $\left(\mathrm{CDCl}_{3}, \tau\right): 2.46\left(1 \mathrm{H}\right.$, s., pyrimidine $\left.\mathrm{C}_{6}-\mathrm{H}\right)$, $4.38\left(2 \mathrm{H}\right.$, broad, $\left.\mathrm{NH}_{2}\right), 5.03\left(2 \mathrm{H}\right.$, broad, $-\mathrm{CH}_{2}$ $\mathrm{N}), 5.83$ and 7.16 (each $2 \mathrm{H} \mathrm{t},-\mathrm{CH}_{2} \mathrm{CH}_{2} \mathrm{O}-$ ), 7.50, 7.96, 7.98, 8.05 and 8.11 (each $3 \mathrm{H}$ s., four $\mathrm{CH}_{3}$ ).

Reaction of 2-Phenyloxalylthiamine (Ia) with 2,6-Dichlorophenol Indophenol Sodium Salt (II)

A saturated ethanol solution of 2,6-dichlorophenol indophenol sodium salt (II) was added dropwise to a stirred suspension of 2-phenyloxalylthiamine (Ia) (778 mg, $2 \times 10^{-3}$ mole) in 50 $\mathrm{ml}$ of abs. ethanol at room temperature under a nitrogen stream. Reduction of II proceeded almost spontaneously and the dropwise addition of II was stopped after ca. thirty seconds when the decolorization of II was complete. After additional stirring for one minute, the reaction mixture was acidified by adding $5 \%$ hydrochloric acid at $0^{\circ}$, then extracted with chloroform. The acid layer was concentrated to dryness by vacuum evaporation to give a white crystalline residue which was recrystallized from methanol to give $181 \mathrm{mg}(27 \%)$ of thiamine hydrochloride (IV) which was identified with an authentic specimen by comparison of IR spectra. The chloroform layer was washed with $5 \% \mathrm{NaOH}$ solution and with water, then dried over anhyd. $\mathrm{Na}_{2} \mathrm{CO}_{3}$ and evaporated to leave a pale yellow oily residue. The residue was passed through a $\mathrm{SiO}_{2}$ column and eluted with n-hexane to give phenylglyoxylic acid ethyl ester (IIIa) $(85 \mathrm{mg}, 24 \%)$ as an essentially pure oil and identified with an authentic sample by IR spectrum and by vpc analysis. The alkali layer was acidified and then re-extracted with chloroform. The chloroform extract was washed with water, dried over anhyd. $\mathrm{Na}_{2} \mathrm{SO}_{4}$ and evaporated to leave a yellow gummy residue which gradually crystallized giving 4,4'-dihydroxy-3,5dichlorodiphenylamine (V) $(134 \mathrm{mg}, 25 \%$ of equivalent moles), mp. $175-178^{\circ}$, which was identified with an authentic specimen prepared by $\mathrm{NaBH}_{4}$ reduction of II.

Reaction of 2-Methyloxalythiamine (Ib) with 2,6-Dichlorophenol Indophenol Sodium Salt (II)

2-Methyloxalylthiamine $(\mathrm{Ib})\left(648 \mathrm{mg}, 2 \times 10^{-3}\right.$ mole) was oxidized by 2, 6 -dichlorophenol indophenol sodium salt (II) in $50 \mathrm{ml}$ of EtOH according to the same procedure as employed for Ia. After acidification by adding $5 \%$ hydrochloric acid, the reaction mixture was extracted with chloroform. The acid layer, on evaporation under reduced pressure, gave a crystalline mass which was recrystallized from $\mathrm{MeOH}$ to give thiamine hydrochloride (IV) (234 mg, $35 \%$ ). The chloroform layer was extracted with $5 \%$ $\mathrm{NaOH}$ solution, washed with water, dried over anhyd. $\mathrm{Na}_{2} \mathrm{CO}_{3}$, and evaporated to give a trace amount of gummy residue, from which no significant crystalline material was obtained by the action of 2, 4-dinitrophenylhydrazine. From the alkali layer, after acidification and extraction with chloroform, 4, 4'-dihydroxy-3, 5-dichlorodiphenylamine (V) $(107 \mathrm{mg}, 20 \%$ of equivalent moles) was obtaind.

Reaction of 2-Phenyloxalylthiamine (Ia) with Trityl Chloride (VII)

$398 \mathrm{mg}\left(10^{-3} \mathrm{~mole}\right)$ of Ia and $278 \mathrm{mg}\left(10^{-3}\right.$ mole) of (VII) were added to $20 \mathrm{ml}$ of $\mathrm{EtOH}$, and the mixture was stirred for 20 hours at room temperature under nitrogen stream. The precipitated crystals were collected by filtration and washed with acetone to give thiamine 
monochloride (VIII) (72 mg, $24 \%$ ) which was identified with an authentic specimen by IR spectra comparison. The filtrate was concentrated under reduced pressure and the resulting oily residue was passed through a $\mathrm{SiO}_{2}$ column and eluted with chloroform. From the first fraction, $130 \mathrm{mg}$ of a mixture of triphenylmethane (IX) and triphenylmethyl ethyl ether (X) was obtained. NMR spectrum $\left[\left(\mathrm{CDCl}_{3}, \tau\right)\right.$ : 1.4-2.0 (ca. $3 \mathrm{OH}$, m., $6 \times \mathrm{C}_{6} \mathrm{H}_{5}$ ), 4.46 (ca. $1 \mathrm{H}$, s., $-\stackrel{1}{\mathrm{C}} \mathrm{H}$ ), 6.89 (ca. $2 \mathrm{H}, \mathrm{q} ., \mathrm{J}=7 \mathrm{cps}, \mathrm{O}-\mathrm{CH}_{2}$ ), 8.80 (ca. $3 \mathrm{H}$, t., $\left.\left.-\mathrm{CH}_{3}\right)\right]$ and vpc analysis of the mixture confirmed the mixture ratio. From the second fraction, $36 \mathrm{mg}(20 \%)$ of phenylglyoxylic acid ethyl ester (IIIa) was obtained. From the third fraction, $5 \mathrm{mg}$ of a crystalline compound (mp. 155-157 ${ }^{\circ}$ ) was obtained and identified with an authentic specimen of triphenylcarbinol (XI) by IR spectra comparison.

Reaction of 2-Phenyloxalylthiamine (Ia) with 2-Methyl-3-benzylideneindolenium Hydrogen Sulfate (XII)

A mixture of $398 \mathrm{mg}\left(10^{-3}\right.$ mole $)$ of Ia and $317 \mathrm{mg}\left(10^{-3} \mathrm{~mole}\right)$ of (XII) in $20 \mathrm{ml}$ of $\mathrm{EtOH}$ was stirred for 20 hours at room temperature under a nitrogen stream. The reaction mixture was then concentrated under reduced pressure to give a light brown residue, which was extracted with chloroform after addition of 20 $\mathrm{ml}$ of water. The chloroform extract was washed with water, dried over anhyd. $\mathrm{Na}_{2} \mathrm{SO}_{4}$ and evaporated to leave a brown residue which was then passed through a $\mathrm{SiO}_{2}$ column and eluted with chloroform to give phenylglyoxylic acid ethyl ester (IIIa) (27 mg, $15 \%$ ) and 2 methyl-3-benzylindole (XIV) ( $2 \mathrm{mg}$, mp. 119$120^{\circ}$ ), identified with an authentic specimen prepared according to literature (15) by comparison of IR spectra. Other unidentified products were eluted with AcOEt as a mixture which could not be purified. $\mathrm{BaCl}_{2}$ solution was added to the water layer remaining from the chloroform extraction to precipitate sulfate ion, then the solution was filtered and the filtrate was concentrated under reduced pressure to give thiamine hydrochloride (64 mg, $19 \%$ ).

Reaction of 2-Phenyloxalylthiamine ( $I a)$ with N-Methylnicotinamide Chloride (XV)
A mixture of $398 \mathrm{mg}\left(10^{-3} \mathrm{~mole}\right)$ of (Ia) and $172 \mathrm{mg}\left(10^{-3} \mathrm{~mole}\right)$ of $(\mathrm{XV})$ in $20 \mathrm{ml}$ of $\mathrm{EtOH}$ was stirred for 24 hours at room temperature under a nitrogen stream. The precipitated solids were collected by filtration and recrystallized from $\mathrm{EtOH}$ to give thiamine monochloride (VIII) (30 mg, $10 \%)$. The filtrate was concentrated under reduced pressure and the resulting residue was passed through a $\mathrm{SiO}_{2}$ column and eluted with chloroform to give IIIa $(27 \mathrm{mg}, 15$ $\%)$. Considerable amounts of brown coloring substance remained in the column even after elution with AcOEt, in which eluate no significant product was obtained.

Reaction of Phenylglyoxal Monohydrate (XVII) with 2,6-Dichlorophenol Indophenol Sodium Salt $(I I)$ in the Presence of TPP and Triethylamine

$1.52 \mathrm{~g}\left(10^{-2} \mathrm{~mole}\right)$ of (XVII) was dissolved in ethanol, then $958 \mathrm{mg}\left(2 \times 10^{-3} \mathrm{~mole}\right)$ of TPP (monohydrate) and $1.0 \mathrm{~g}\left(10^{-2} \mathrm{~mole}\right)$ of triethylamine $\left(\mathrm{NEt}_{3}\right)$ were added to the solution under a nitrogen stream at $35 \pm 2^{\circ}$. To this mixture, crystals of 2,6-dichlorophenol indophenol sodium salt (II) were gradually added untill the decolorization of (II) was complete, then the solution was stirred for 3 hours at the same temperature. The reaction mixture was concentrated under reduced pressure to give a yellow gummy residue which was dissolved in $30 \mathrm{ml}$ of water and extracted with ether. The ether extract was washed with $5 \% \mathrm{NaOH}$ solution then with water, dried over anhyd. $\mathrm{Na}_{2} \mathrm{CO}_{3}$, and concentrated to leave a pale yellow oil which was purified by passing through a $\mathrm{SiO}_{2}$ column with ether to give $443 \mathrm{mg}(25 \%)$ of phenylglyoxylic acid ethyl ester (IIIa) as a colorless oil.

\section{REFERENCES}

1. Knox, W. E., in P.D. Boyer, H. Lardy, and K. Myrbäck (Editors), The Enzymes, Vol. 2, Ed. 2, Academic Press, New York, (1960). p. 253.

2, Monder, C, J. Biol. Chem., 242, 4603 (1967).

3. Salem, H. M., Archiv. Biochem. Biophys., 57, 20 (1965).

4. Sato, A., Tohoku J. Exp. Med., 83, 103 (1964).

5. Wako, H., Tohoku J. Exp. Med., 55, 34 (1951).

6. Takamizawa, A., Matsumoto, S., and Sakai, S.. Tetrahedron Letters. 2189 (1968). 
7. Takamizawa, A., Matsumoto, S., and Sakai, S., Chem. Pharm. Bull.. 17, 128 (1969).

8. Krampitz, L. O., Ann. Rev. Biochem., 38, 213 (1969).

9, Daigo, K. and Reed, L. J., J. Amer. Chem. Soc., 84, 659 (1962).

10. Nash, C. P., Olsen, C. W., White, F. G. and Ingraham, L. L., J. Amer. Chem. Soc., 83, 4106 (1961).

11. Breslow, R. and McNelis, E., J. Amer. Chem. Soc., 82, 2394 (1960).
12. Bruice, T.C. and Benkovic, S. J., Bioorganic Mechanism, Vol. 2, p. 301. Benjamin, Inc., New York, (1960).

13. Schellenberg, K. A., J. Biol. Chem., 242, 1815 (1967).

14. Hino, T. and Nakagawa, M., J. Amer. Chem. Soc., 91, 4598 (1969).

15. Huffman, R.W. and Bruice, T. C., J. Amer. Chem. Soc., 89, 6243 (1967).

16. Burr, G. O. and Gortner, R.A., J. Amer. Chem. Soc., 45, 1224 (1924). 